\title{
Beam Break Unit
}

National Cancer Institute

\section{Source}

National Cancer Institute. Beam Break Unit. NCI Thesaurus. Code C129002.

The unit of measure for the number of times in which light paths are interrupted by movement. 